\title{
PENDAMPINGAN PROMOSI PARIWISATA DESA SUMBER REJO PURWOSARI PASURUAN (JEMPINANG RAFTING)
}

\author{
Mohammad Zainul Rojikin'), Nurma Yuwita ${ }^{2)}$ \\ Universitas Yudharta Pasuruan \\ 1) samjainul1987@gmail.com
}

\begin{abstract}
Abstrak: Di era pandemi seperti ini, pariwisata di mana-mana terkena dampak yang sama, penurunan jumlah pengunjung yang signifikan dan juga kerugian besar yang dialami oleh pengelola pariwisata menjadikannya pr besar untuk terus ditingkatkan. Dalam mengalami pandemi seperti ini harus dilakukan promosi agar pengunjung tetap datang ke wisata tersebut dan juga kestabilan pengelola dan pedagang di tempat wisata tetap sejahtera. Oleh karena itu penulis melakukan Praktek Kerja Nyata (PKN) dalam membantu promosi wisata pedesaan yang fokus pada media sosial antara lain Facebook, Instagram, Tik Tok, dan media berita. Sehingga wisata arung jeram jempinang akan lebih dikenal oleh masyarakat di seluruh Indonesia. Dari penggunaan ketiga media tersebut, Instagram lebih dominan untuk promosi di media sosial karena banyak pengguna media sosial yang menciptakan minat baru yaitu promosi melalui media sosial. Yang kedua ditempati oleh aplikasi Tik Tok dan yang ketiga adalah media berita.
\end{abstract}

Kata kunci: Pariwisata, Rafting, PKN

\begin{abstract}
In an era of pandemics like this, tourism everywhere is subject to the same impact, a significant drop in the number of visitors and also the large losses experienced by tourism managers make it a big pr to continue to improve. In experiencing a pandemic like this, promotions must be carried out so that visitors continue to come to these tours and also the stability of managers and traders in tourist attractions remains prosperous. Therefore, the authors carry out Real Work Practices (PKN) in assisting rural tourism promotion that focuses on social media including Facebook, Instagram, Tik Tok, and news media. So that the jempinang rafting tour will be better known by people throughout Indonesia. From the use of these three media, Instagram is more dominant for promotion on social media because many social media users have created new interests, namely promotion through social media. The second is occupied by the Tik Tok application and the third is the news media.
\end{abstract}

Keywords: Tourist, Rafting, PKN

\section{PENDAHULUAN}

Jempinang Rafting merupakan salah satu tempat river tubing terbaik di Pasuruan. Sungainya yang di kenal oleh masyarakat setempat yaitu kali jempinang yang panjang nya 
mencapai $20 \mathrm{~km}$ dengan debit air yang lumayan deras dengan mata air sumber alami yang sangat jerni dan segar. Jempinang Rafting terletak di desa Sumberejo kecamatan Purwosari kabupaten Pasuruan. Hijaunya persawahan akan menghiasi selama perjalanan Anda. dimana rafting jempinang berketeria fun rafting yang mana arus nya santai tetapi banyak jeram yang menantang oleh jeram yang menguji adrenalin kita.

Di era pandemi seperti ini pariwisata di manapun kena dampak yang sama, merosotnya jumlah pengunjung yang signifikan dan juga kerugian yang besar yang di alami pengelola wisata menjadikan pr besar untuk terus berbenah. Dalam mengalami masa pandemi seperti ini promosi-promosi harus tetap di lakukan agar tetap pengunjung mendatangi wisata tersebut dan juga kestabilan pengelola dan pedagang di tempat wisata tetap sejahtera.

Pada umumnya pariwisata dimanapun pasti memiliki media promosi, antara lain promosi mengunakan media ada juga mengunakan banner, poster dan lain sebagainya. Dengan adanya promosi pariwisata tersebut banyak di kenal dan di bicarakan orang sehingga pariwisata tersebut akan ramai di kunjungi wisatawan tersebut.

Dengan adanya kemajuaan teknologi saat ini berkembang sangat pesat, ditambah laju melesatnya berbagai informasi dsb. Hal ini turut berpengaruh terhadap perkembangan promosi pada media, degan mengunakan media social seperti, Facebook, Instagram, Tik tok, serta pemberitaan online akan memudahakan pengelola pariwisata untuk mempromosikan wisatanya melalui media.

Maka dari itu penulis melaksanakan Praktek Kerja Nyata (PKN) pada pendampingan promosi pariwisata desa yang fokus di media social meliputi Facebook, Instagram, Tik tok, dan media pemberitaan. Sehingga wisata rafting jempinang akan lebih di kenal oleh masyarakat seluruh Indonesia.

\section{METODE}

Metode pelaksanaan Praktek Kerja Nyata (PKN) yang dilakukan di Rafting jempinang yaitu dengan mengetahui aktivitas sesuai dengan kondisi lapangan. Adapun proses pelaksanaan penggalian data dilakukan Studi Lapangan. Proses ini dilakukan di lokasi praktek kerja nyata selama satu bulan. Proses studi lapaangan ini dilakuan untuk menggali informasi terkait wisata jempinang rafting. Adapun cara pengumpulan datanya melaui: 1 . 


\section{Khidinatuina \\ Jurnal Penelitian dan Pengabdian Hepada Masularahat}

Institut Agama Islam Sunan Kalijogo Malang

P-ISSN: 2721-9607/ E-ISSN: 2721-947X

Volume 2 Nomor 2 Desember2021

Wawancara dengan pihak yang terkait seperti pengelola tempat dan menjelaskan sedikit tentang latar belakang wisata jempinang itu bagaimana. Kita menggali infomasi tentang kekurangan yang ada di wisata rafting jempinang dan juga seberapa banyak nya wisatawan yang berkunjung di sana.2. Observasi Teknik pengumpulan data dengan secara langsung terjun ke tempat tersebut dengan melihat lokasi dan juga mewawancarai pengelola dan tim yang ada di sana, sehinga kita mengetahui apa yang kurang di sana. 3. Dokumentasi dilakukan sebagai proses pengambilan data dari wisata rafting jempinang dengan melakukan foto di sepot-sepot tertentu sehingga kita dapat mengetahui apa saja keunikan dan keunggulan di wisata tersebut . kemudian data-data dokumentasi yang telah diperoleh, dipelajari untuk di tarik kesimpulan

Contoh Diagram:

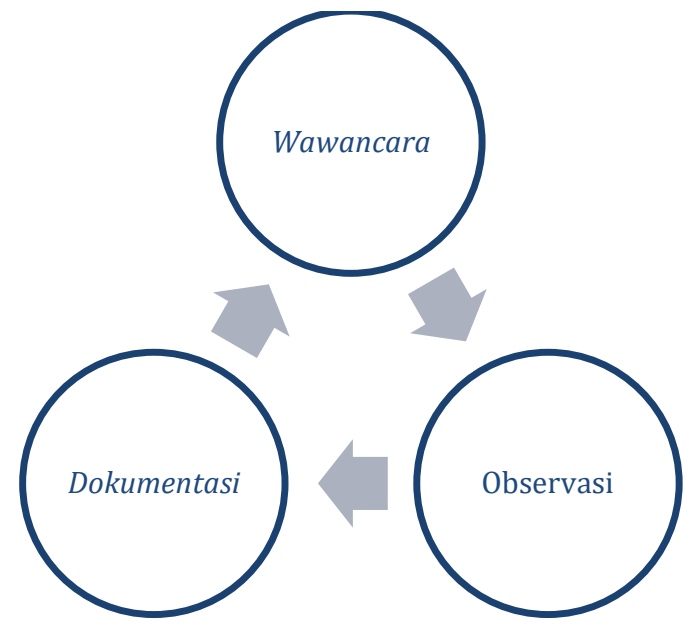

Gambar 1. Contoh Diagram

(Gambar harus diberikan penomoran, contohnya: Gambar 1. Contoh Diagram. Keterangan gambar (nomor dan judul gambar) diletakkan di tengah bawah)

\section{Hasil dan Diskusi}

Tahapan demi tahapan pelaksanaan PKN sudah berlangsung dengan mengunakan metode wawancara dan juga observasi kemudian dokumentasi sudah seesai di laksanakan sesuai jadwal yang telah ditetapkan. Dengan hasil pembuatan social media yang baru dan juga pelatihan admin media social dan juga pendampingan pariwisata yang telah sukses di lakukan. 


\section{Pendampingan Pembuatan Akun Instagram}

Melakukan pendampingan pembuatan akun instagram baru dikarenakan instagram yang lama ber namakan @jempinang_Rafting yang sudah off terakhir pada tangal 6 maret 2020 maka dari itu kita membuatkan akun instagram kembali sehingga promo-promo di lakukan di instagram terbaru tersebut @jempnangrivertubing

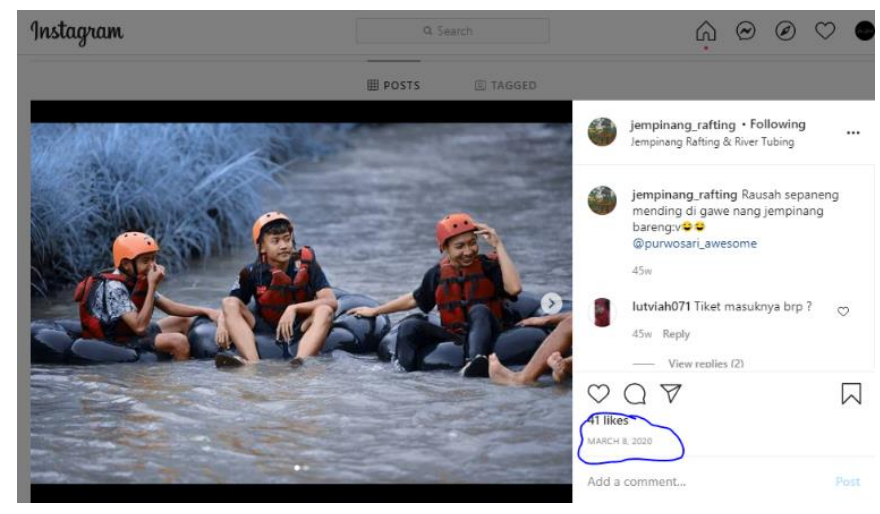

Gambar 1. Akun instagram lama yang terakhir Off bulan 8 Maret 2020

Dengan pendampingan pembuatan akun istagram baru maka di harapkan promosi melalui social media tetap dilakukan walaupun dalan keadaan pandemic Covid-19. Sehingga wisatawan tetap mendatangi wisata rafting jempinang.

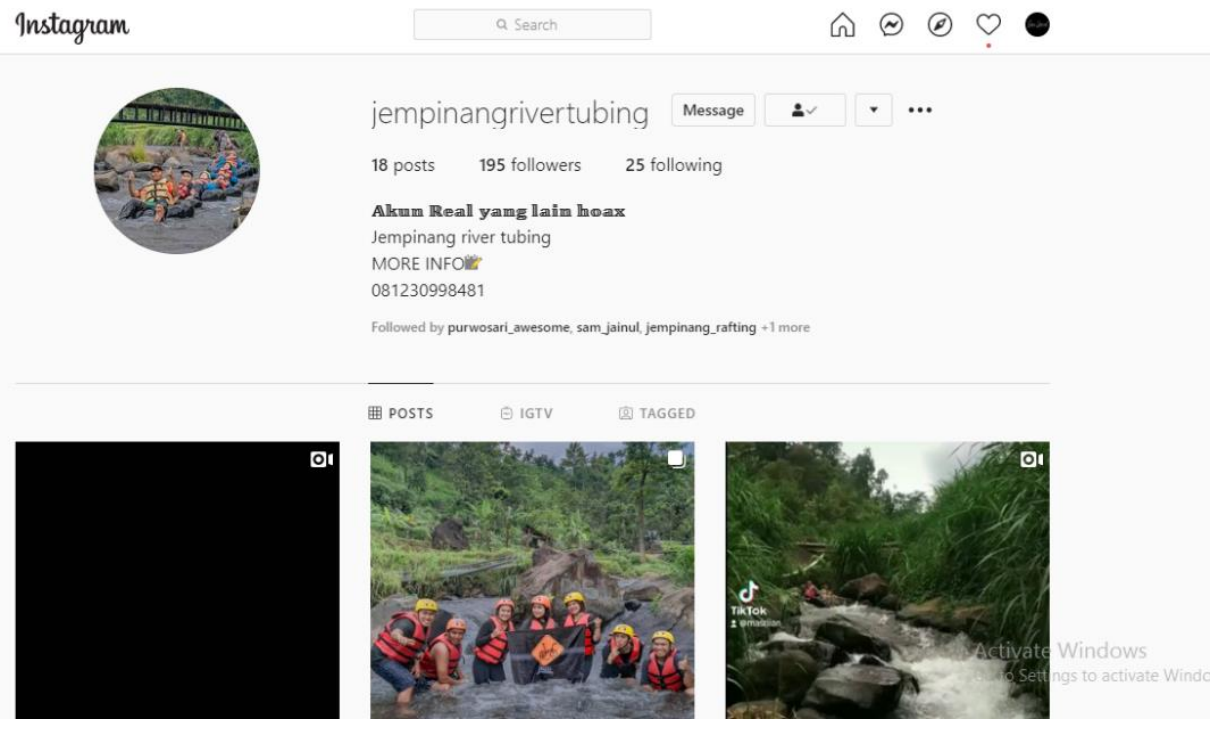

Gambar 2. Akun instagram baru dengan nama @jempinangrivertubing 


\section{Khidinatuna \\ Jurnal Penelitian dan Pengabdian Hepada Masularahat}

\section{Institut Agama Islam Sunan Kalijogo Malang}

P-ISSN: 2721-9607/ E-ISSN: 2721-947X

Volume 2 Nomor 2 Desember2021

Dan pada tangal 18 desember 2020 awal uplod di istagram di lakukan dengan melakukan tag ke teman" agar supaya semua mengetahui akun instagram tersebut

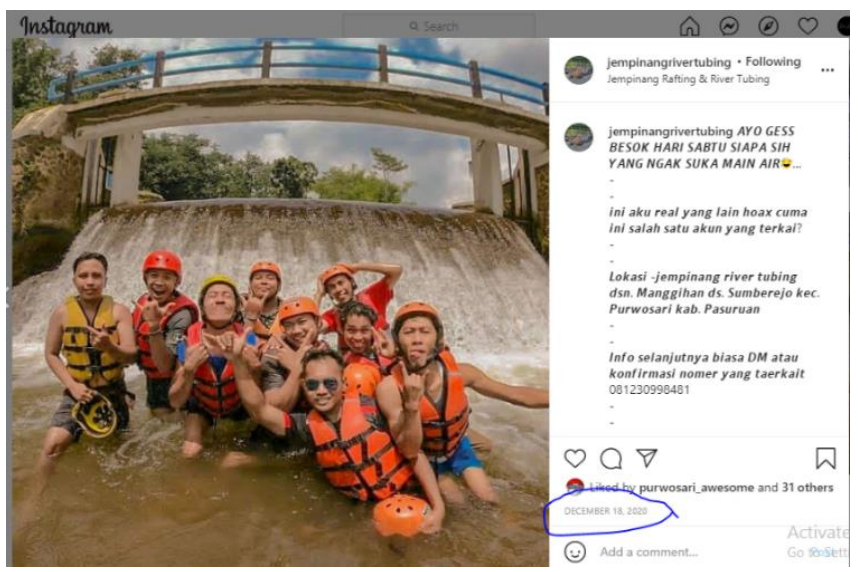

Gambar 2. Uplod pertadana pada tangal 18 desember 2020

Dengan terus uplod instagram secara rutin, wisatawan di jempinang rafting semakin bertambah pengunjung nya walaupun dalam keadaan pandemic.dan juga kolaborasi dengan media local purwosari juga menambah respon positif penguna social media.

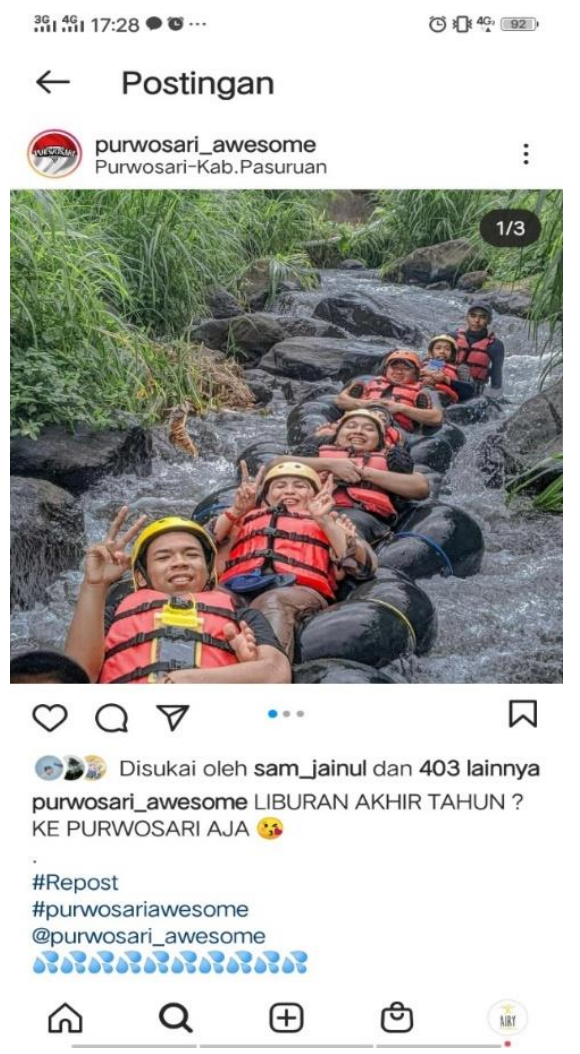




\section{Klyidmatuna}

Jurnal Penelitian dan Pengabdian Hepada Masuarahat

\section{Institut Agama Islam Sunan Kalijogo Malang}

P-ISSN: 2721-9607/ E-ISSN: 2721-947X

Volume 2 Nomor 2 Desember2021

Gambar 2.Salah satu foto yang di repost media @purwosari_awesome

Selain media lokal purwosari media besar seperti @pasuruanapik juga mempromosikan wisata rafting jempinang

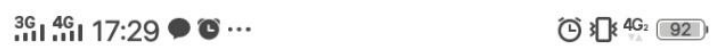

$\leftarrow$ Postingan

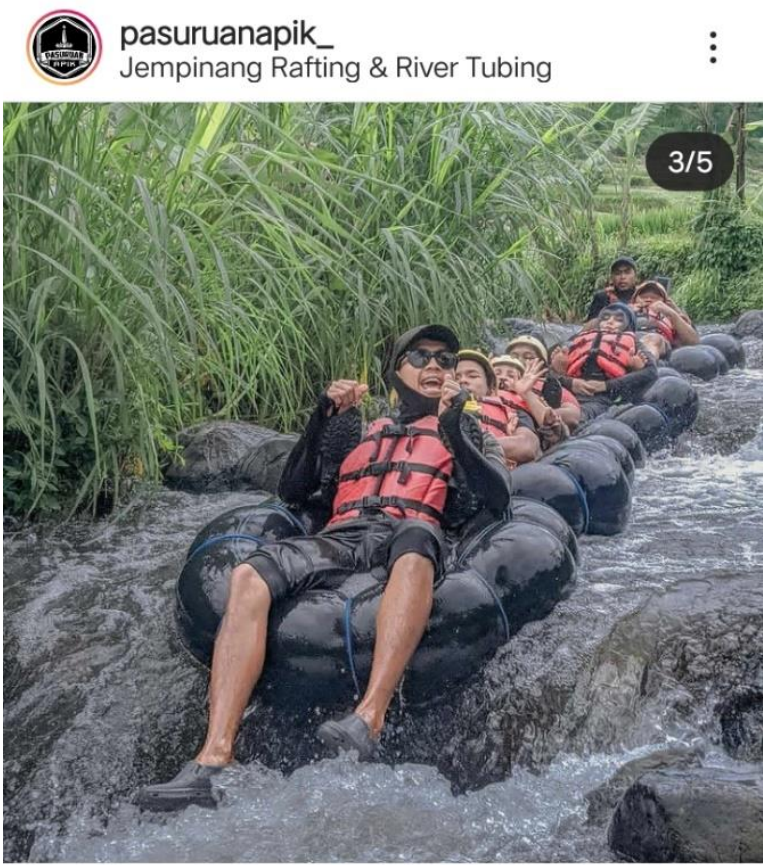

$\bigcirc \bigcirc \nabla \cdots \cdots$

(2) Disukai oleh hidaa26 dan 919 lainnya

pasuruanapik_Loh loh loh, dolanan banyu kyok.e seru yo rek..

Sopo sng wes tau nyoba rivertubingan nng kene?

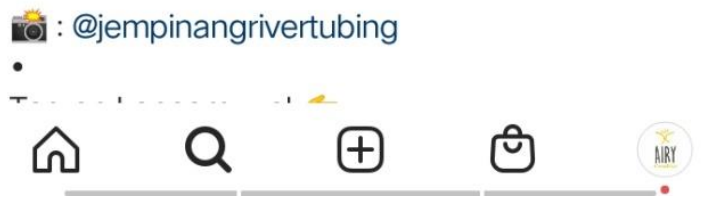

Gambar 2. Salah satu foto yang di repost media @pasuruanapik_

Dengan komentar para penguna instagram yang positif tim admin instagram semangat membuat konten untuk di unggah ke instagram 


\section{Khidimatuina \\ Jurnal Penelitian dan Pengabdian Hepada Masuarahat}

Institut Agama Islam Sunan Kalijogo Malang

P-ISSN: 2721-9607/ E-ISSN: 2721-947X

Volume 2 Nomor 2 Desember2021

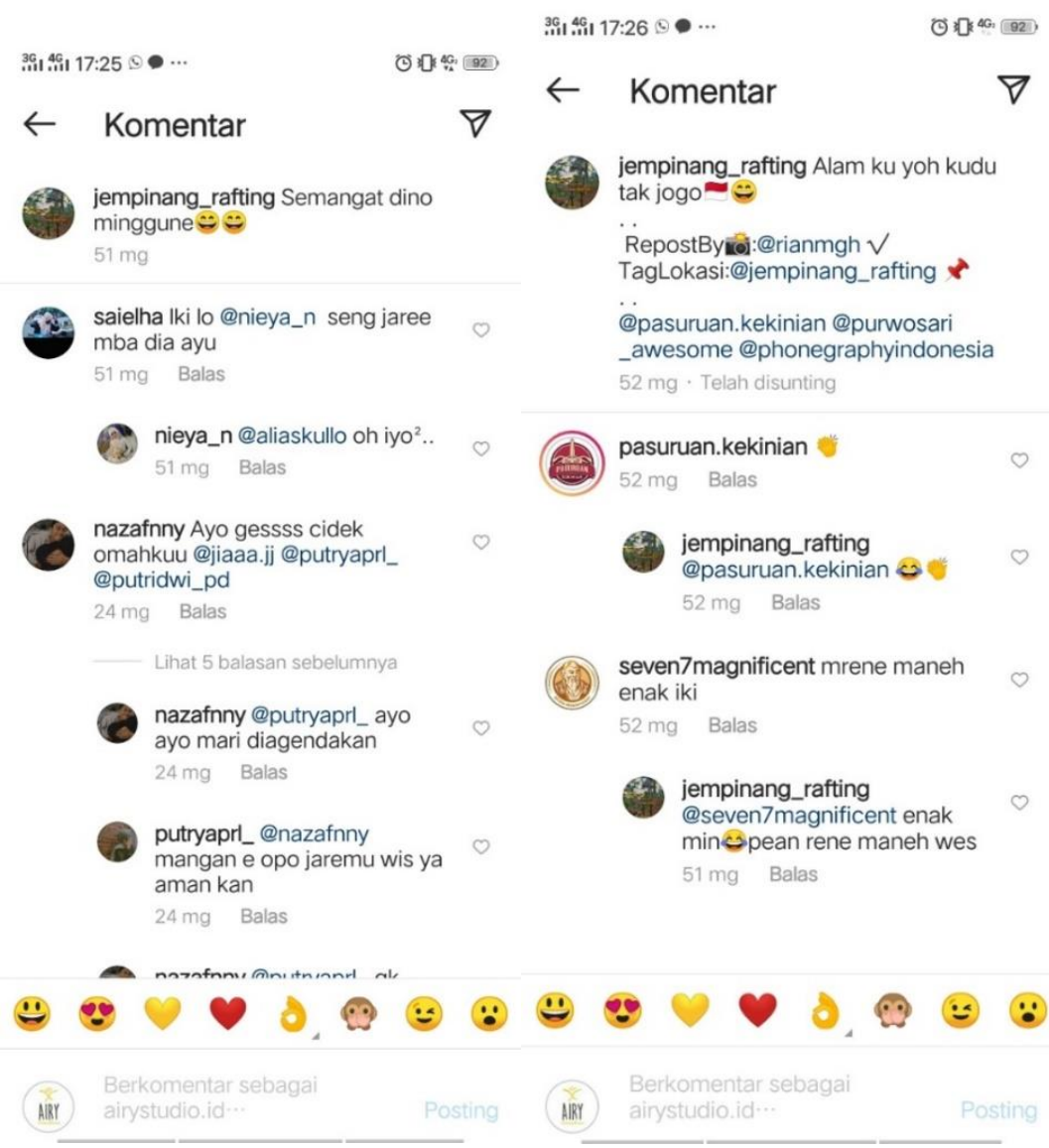

Gambar 2. Respon baik penguna instagram

\section{Pembuatan akun Tik-tok}

Selain media instagram kita menggunakan social media lainnya, seperti tik-tok yang akhir-akhir ini menjadi aplikasi yang trending, dengan system yang sama kita ungah konten yang telah kita buat agar di ketahui semua orang 


\section{Klpidinatuna}

Jurnal Penelitian dan Pengabdian Hepada Masuarahat

\section{Institut Agama Islam Sunan Kalijogo Malang}

P-ISSN: 2721-9607/ E-ISSN: 2721-947X

Volume 2 Nomor 2 Desember2021

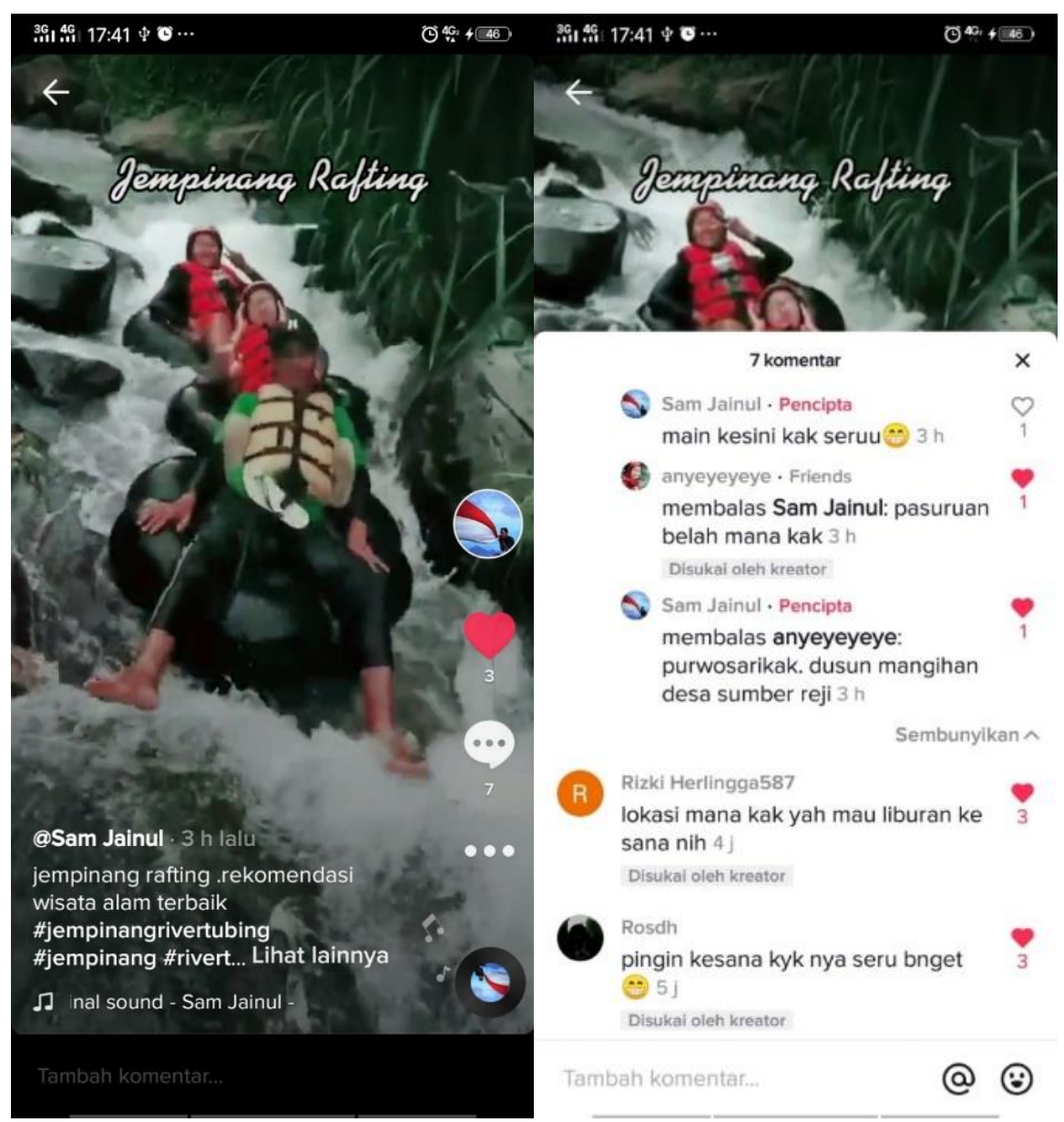

Gambar 2. Unggahan dan juga respon penguna tik-tok

\section{Pembuatan media pemberitaan}

Selain social media, media pemberitaan seperti pemberitaan online juga kita lakukan dengan penulisan berita oleh tim pkn juga sangat membantu dalam melakukan promosi. 


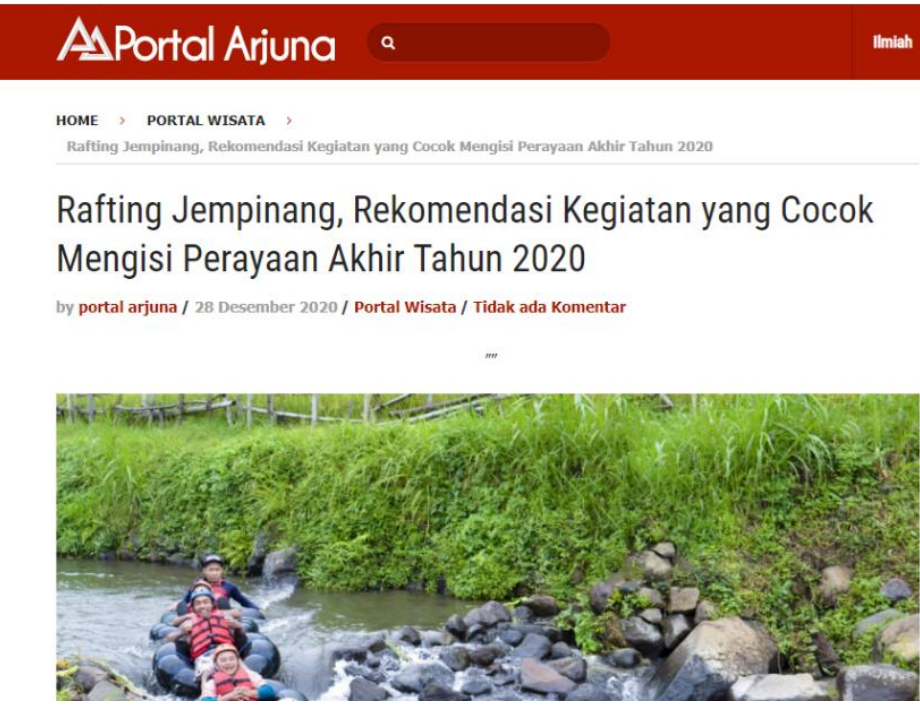

Gambar 2. Pemberitaan di portal arjuna.net

\section{KESIMPULAN}

Jempinang Rafting terletak di desa Sumberejo kecamatan Purwosari kabupaten Pasuruan. Hijaunya persawahan akan menghiasi selama perjalanan anda. dimana rafting jempinang berketeria fun rafting yang mana arusnya santai tetapi banyak jeram yang menantang oleh jeram yang menguji adrenalin kita.

Di era pandemi seperti ini pariwisata di manapun kena dampak yang sama, merosotnya jumlah pengunjung yang signifikan dan juga kerugian yang besar yang di alami pengelola wisata menjadikan pr besar untuk terus berbenah. Dalam mengalami masa pandemi seperti ini promosi-promosi harus tetap di lakukan agar tetap pengunjung mendatangi wisata tersebut dan juga kesetabilan pengelola dan pedagang di tempat wisata tetap sejahtera.

Dengan adanya kemajuaan teknologi saat ini berkembang sangat pesat, ditambah laju melesatnya berbagai informasi dsb. Hal ini turut berpengaruh terhadap perkembangan promosi pada media, degan mengunakan media social seperti, Facebook, Instagram, Tik tok, serta pemberitaan online akan memudahakan pengelola pariwisata untuk mempromosikan wisatanya melalui media.

Maka dari itu penulis melaksanakan Praktek Kerja Nyata (PKN) pada pendampingan promosi pariwisata desa yang fokus di media social meliputi Facebook, Instagram, Tik tok, 
dan media pemberitaan. Sehingga wisata rafting jempinang akan lebih di kenal oleh masyarakat seluruh Indonesia.

Dari penggunaan ke tiga media tersebut media instagram lebih dominan untuk melakukan promosi di media social karena banyaknya pengguna media sosial menumbuhkan kepentingan baru yaitu berpromosi melalui media sosial. Yang kedua di duduki oleh aplikasi tik tok dan yang ketiga adalah media pemberitaan

a. Instagram

Keunggulan promosi melalui Instagram adalah cakupannya luas karena Instagram menggunakan fasilitas online dan terhubung dimanapun.dan juga dari hasil posting an kita yang selalu di respon banyak oleh pengguna social media kita lihat dari jumlah kunjungan di profil kita dan juga banyak nya jumlah LIKE dan juga Komentar positif.

b. Tik tok

Pemanfaatan media tiktok juga sangat baik sebagai media promosi kita Seperti yang kita ketahui TikTok sedang berkembang pesat di Indonesia dan bahkan melebihi sosial media lainnya, misalnya Facebook yang saat ini sudah jarang digunakan anak muda. Namun setelah kita analisis tik tok masih kalah dengan instagram karena respon pengguna social media masih sedikit.

c. Media pemberitaan portal arjuna

Penggunaan media pemberitaan juga perlu di lakukan karena untuk menyebar luaskan keberadaan di mana rafting jempinang itu namun juga masih kalah dengan media social instagram dan juga tik tok terlihat di view yang kita lihat di wab portal arjuna.

\section{Ucapan Terima Kasih/Acknowledgements}

Segala puji dan syukur hanya milik Allah subhanahu wa ta'ala, pada kesempatan ini tim ingin mengucapkan terima kasih atas bantuan dari berbagai pihak yang sangat berperan dalam berproses penyusunan pengabdian masyarakat, oleh karena itu, dengan rasa penuh hormat, tulus dan ikhlas tim PKN mengucapkan terima kasih kepada: Tuhan Yang Maha Kuasa, karena berkat dan rahmat karunia-Nya tim PKN dapat menyelesaikan laporan pengabdian masyarakat, Pak Nuli sebagai penangung jawab jempinang rafting.

Terimakasih karena sudah diterima dengan baik untuk melakukan penelitian. Akhir kata dengan segala keterbatasan penulis, semoga kita semua mendapat balasan atas seluruh kebaikan-kebaikan kita dari Allah Subhanahu Wa Ta’ala. Amin. 


\section{Khidinatuina \\ Jurnal Penelitian dan Pengabdian Hepada Masularahat}

Institut Agama Islam Sunan Kalijogo Malang

P-ISSN: 2721-9607/ E-ISSN: 2721-947X

Volume 2 Nomor 2 Desember2021

\section{DAFTAR PUSTAKA}

https://www.songarafting.com/tentang-kami/

https://portalarjuna.net/2020/12/rafting-jempinang-rekomendasi-kegiatan-yang-cocokmengisi-perayaan-akhir-tahun-2020/

https://www.google.com/search?q=jempinang\%20river\%20tubing\%20pasuruan $\% 20$ jawa\% 20timur\&oq=jempinang\&aqs=chrome.3.69i57j0l3j0i5i10i30j0i5i30l2j69i60.6772j0j7\& sourceid=chrome\&ie=UTF-13] 